\title{
A formação no horizonte do acontecer primordial do humano: a presença como um dos elementos essenciais
}

\author{
Clenio Lago, Roque Strieder \\ Programa de Pós Graduação em Educação - Mestrado em Educação da Unoesc - Brasil
}

\begin{abstract}
Resumen
Hasta la crisis de la modernidad, o de lo que se llamó de ruptura de la metafísica, el término inclusión estuvo orientado por el discurso de la normalidad, basado en meta narrativas definidoras del cierto y del errado. En este contexto, las diferencias emergen, estimulando el debate acerca de la formación y la inclusión la cual pasa a ser comprendida en el horizonte de la intersubjetividad dialógica. El objetivo, con este ensayo, es tematizar la relación entre inclusión y formación, considerando la importancia del otro en los procesos educativos. Y lo haremos con base en la hermenéutica filosófica, basado en los argumentos de Nietzsche, Heidegger y Gadamer, como manera de indicar la formación como acontecer primordial, que se efectiva en los encuentros y desencuentros, bajo la forma del diálogo profundo la experiencia intersubjetiva emerge como un lugar de origen del origen: outoformativo.

Palavras chave: intersubjetividad; inclusión; formación
\end{abstract}

\section{INTRODUÇÃO}

Onde quer que deparemos com uma moral, encontramos uma avaliação e hierarquização dos impulsos e atos humanos. Tais avaliações e hierarquizações sempre constituem expressão da necessidade de uma comunidade, de um rebanho. [...] Com a moral, o indivíduo é levado a ser função do rebanho e a se conferir valor apenas enquanto função. [...] Moralidade é o instinto de rebanho no indivíduo (NIETZSCHE, 2005, p. 142).

Onde encontrei um ser vivente, lá encontrei vontade de poder. E, este mistério segredou-me a vida: 'Veja', disse ela, 'eu sou aquela que sempre tem de superar a si mesma' (NIETZSCHE, apud GIACOIA JÚNIOR, 2005, 58).

O termo inclusão tornou-se recorrente nos discursos educacionais, políticos, nos processos investigativos. Tornou-se senso comum como uma expressão salvacionista, sem se perguntar o quanto a inclusão pode constituir-se num processo violento, moralizante e impedir a vida como sinaliza o poeta João Cabral de Melo Neto quando no poema Cão sem pluma escreve "o que vive incomoda de vida" e ser incomodado de vida não é ter a vida sob controle, desejo de muitos, mesmo na ideia de não ter controle nenhum. Nesse sentido, perguntamos o que significa inclusão, incluir? Em que medida os processos de inclusão fazem justiça às singularidades? O que constitui os processos inclusivos? Ou ainda, é possível a inclusão, como e que "boa nova" trás o outro que nos chega? Incluir o que, quem, a onde, para que? Podemos ainda, falar em processos inclusivos? Se sim, de que maneira?

Esse problema ganha sentido em meio ao debate contemporâneo da qualidade em educação na medida em que a inclusão e o outro passam a ser vistos como importantes elementos dos processos educativos, num contexto de crise dos referenciais universais, visto questionados. Assim sendo, o outro como diferente modo de ser do eu passa a ser um referencial não somente definidor do eu, senão que questionador, por que é em si outro, simplesmente, outro ai.

Antes, os questionamentos diziam respeito à aplicação das fórmulas corretas de se educar. Agora, a presença de terceiros na lógica formal abre possibilidades nos processos educativos, constitui um importante desafio, pois não há mais um lugar definido previamente, emergindo o humano enquanto entretecimento nos acontecimentos. Por outro lado, nos parâmetros curriculares vêm ganhando espaço o discurso da flexibilidade, em que inclusão, parece significar trazer para dentro, por isso adaptabilidade, se é que ainda podemos falar inclusão. No caso do sistema vigente, está mais para adaptabilidade, maleabilidade ao telos mercadológico, tendo implicações muito pessoais. Embora novas questões estejam emergindo, podemos afirmar com Flickinger (2010, p. 182) que hoje, “[...] o homem vive o sofrimento pelo pesadelo da liberdade”, ou seja, "trata-se de um pesadelo que impede a construção de uma biografia em si coerente e manejável pelo próprio sujeito”.

Frente a esses desafios, o objetivo é a refletir sobre a relação inclusão e formação no emergir do outro, estes terceiros. Para tal abordaremos, de forma mais detalhada, a ruptura da metafísica e suas implicações; o círculo da compreensão como círculo virtuoso, como um possível lugar do acontecer originário da formação como autoformação e por fim, o diálogo como o modo do acontecer humano. Por isso as duas citações acima fazem sentido, na medida em que tencionam os universais e os singulares, permitindo a pergunta: em que medida a inclusão, os processos inclusivos podem fazem justiça ao outro, às singularidades?

Esta reflexão tem sentido, na medida em que "a tradição ocidental freqüentemente percebe a diferença de modo perigoso, destruindo-a e assimilando o estranho sob a reinvindicação da igualdade. Isso porque, na tradição moderna, a auto-afirmação da subjetividade implica em dominar a diferença” (HERMANN, 2001, p. 133). Porque vivemos em um mundo reconhecidamente plural que traz a exigência de educar no desafio do outro 
em sua alteridade, sem a intensão de submetê-lo, contexto em que diversidade é confundida com desigualdade, portanto, é muito mais expressão de conflito do que a possibilidade do humano enquanto temporalidade.

\section{A RUPTURA DA METAFÍSICA E O RECONHECIMENTO DO OUTRO}

Diante da multiplicidade e da dinamicidade, os gregos se perguntavam por referenciais que possibilitassem certezas, segurança às ações. Instituíram a metafísica como um lugar fora da areia movediça da contingência, situação em que os valores passaram a ser alcançados e delineados pela razão e a experiência sensível está subordinada, pois o outro é definido a partir da identidade e para a identidade. Os medievais, subsumidos pela teologia, pelo telos educativo, na forma de crença em Deus como o outro absoluto, justificada aos moldes do modelo neoplatônico, também estão no horizonte da metafísica. Assim,

Os ideais éticos gregos buscam a plena e
perfeita realização humana, a ser obtida
pela razão, enquanto que a tradição cristã
traz ideais em que o homem depende
totalmente de um Deus único e criador,
que se revela como verdadeiro fim. A ética
cristã encontra em Jesus Cristo o modelo
absoluto de perfeição humana
(HERMANN, 2001, p. 30).

Com a crise do paradigma medieval e do ideal de homem divino, busca-se, no homem, na razão objetiva o novo referencial, as condições transcendentais de certeza, não tendo espaço ao outro da razão, a emoção. Mas os efeitos históricos da razão pretensamente pura, aos poucos, mostram-se não tão razoáveis e entra em crise a razão moderna, revelando-se com ela os limites do sujeito moderno e de suas certezas, consequentemente, os limites do ideal de homem racional, sob o qual se estruturou o mundo ocidental e sob o qual incluir significa adequar, adaptar. Isso na medida em que objetivou sujeitos autogovernados. Assim, a crise que chamamos de crise da modernidade é, na verdade, a crise do modo metafísico de pensar que separa sujeito do objeto, homem da natureza, teoria da prática, o formal do sensível, aquele que sabe daquele que não sabe, o professor do aluno. É a crise do ideal de homem racional, tido como fim último, da razão pura como garantidora da verdade. Na educação, é a crise do telos, do referencial, do ideal educativo articulado em torno do ideal de homem racional.

Para melhor elucidar o significado desta crise acima sinalizada, bem como seus impactos para a educação indicamos as argumentações de Nietzsche, o grande anunciador da morte de Deus, que se pergunta como surgiu a lógica na mente humana e responde:

Certamente do ilógico, cujo domínio deve ter sido enorme no princípio. [...] Mas a tendência predominante de tratar o semelhante como igual - uma tendência ilógica, pois nada é realmente igual - foi o que criou todo fundamento para a lógica. [...] por muito tempo foi preciso que o que há de mutável nas coisas não fosse visto nem sentido (NIETZSCHE, 2005a, p. 139).

Ao expor a lógica estrutural da racionalidade moderna como sendo ilógica, Nietzsche elucida o centro nuclear da modernidade como um particularismo universalizado desde uma vontade de poder que se institui e buscou se universalizar enquanto tal. Vale ressaltar que não foi suficiente evidenciar a lógica da lógica como sendo ilógica, Nietzsche precisou implodir o referencial conceitual de perfeição e de identidade, emergido desde então: Deus - Javé - aquele que É ao afirmar que não existem fatos, verdade, apenas interpretações. E bradou fortemente: "O mais forte e mais sagrado que o mundo até então possuíra sangrou inteiro sob os nossos punhais [...] [e, com propriedade anunciou:] Nunca houve um ato maior - e quem vier depois de nós pertencerá, por causa desse ato, a uma história mais elevada que toda a história até então!” (NIETZSCHE, 2005a, p. 147-148). Eis o desafio.

Nietzsche coloca em questão tanto a crença na origem divina da verdade como o seu valor absoluto, como a ideia de verdade abstrata em si, e, por decorrência, a unidade metodológica, o “[...] modo tipicamente metafísico de pensar” (GIACOIA JUNIOR, 2000, p. 24). Evidencia “[...] o caráter fictício da própria moral, da religião e da metafísica e o desencanto é a tomada de consciência de que não há estrutura, leis e valores objetivos" (HERMANN, 2001, p. 73).

A ruptura da metafísica implica compreender que não mais existem verdades absolutas, modelos ideais, mas possibilidades, perspectivas, interpretações, a realidade acontecendo. Como também, "não existe Coisa-em-si, nenhum conhecimento absoluto; o caráter perspectivista, ilusório, enganador é intrínseco à existência” (NIETZSCHE, 1989, p. 77). Contexto em que, o “'Eu’ trata-se de uma hipótese auxiliar com vista à inteligência do mundo” (NIETZSCHE, 1989, p. 73) e não como algo em si autofundado, senão que constitui um mundo em acontecimento. Sendo assim, Nietzsche (1989, p. 88) se pergunta: "Em que pode unicamente consistir o conhecimento? 'Interpretação', de modo algum ‘explicação'”, responde.

$\mathrm{O}$ questionamento da verdade como algo "em si” efetivado por Nietzsche destituiu o referencial do "eu pontual” defendido por Descartes, o eu transcendental kantiano, bem como a ideia de espírito absoluto apresentado por Hegel, obrigando a filosofia a incorporar o problema da contingência e da aparência há muito desvalorizado no discurso filosófico. Isso porque o anúncio da morte de Deus abalou os fundamentos objetivos e subjetivos da modernidade, a ideia de verdade e de sujeito ensejou o ressurgimento da experiência do trágico, colocando no lugar do "tu deves" o "eu quero" como vontade de potência, a afirmação da vida e a da moral como criação, perspectiva em que o homem é a própria obra de arte se fazendo arte. De certa forma, 
Nietzsche se volta às contribuições dos pré-socráticos, especialmente, às tragédias gregas.

Nesse contexto, a medida transforma-se em desmedida mediante o esquecimento e o dinamismo da realidade, para emergir como medida e novamente como desmedida. "Um crepúsculo dos deuses era eminente" (NIETZSCHE, 2005b, p. 24). Agora, radicaliza-se a autodeterminação individual como referência sobre o bem e o mal. A vontade é apresentada como soberana de si no lugar da razão, como o impulso básico a novos valores. É eliminada a representação concebida idealmente na arte apolínea esta que, desde a arte milimetricamente concebida, exigia e assegurava um horizonte à formação. Em seu lugar assume a arte dionisíaca, a arte vivencial. Dessa forma, o modo de ser passa a ocorrer no arrebatamento artístico da desmedida dionisíaca, que conjuga o sensível e o formal como experiência estética e permite o outro enquanto outro aparecer em perspectiva, como possibilidade, não mais dentro de uma estrutura desejável. Somos levados a consideramos o outro como ser-aí, como sendo consequentemente o nosso eu.

A exigência agora é que o homem precisa orientar, viver sua vida a partir de novos valores que não sejam os já estabelecidos culturalmente até então e dados como prontos e imutáveis, visto que esses estão desgastados e não servem mais. É preciso, acima de tudo, partir daqueles princípios que estejam voltados à afirmação da vida, para além da moral de rebanho, para além do bem e do mal: ser fiel a terra. Seu filosofar exige espírito livre como o espírito da criança que manifesta com sinceridade seus desejos, suas simpatias e antipatias. Isso porque, para Nietzsche, a racionalidade ocidental, configurada com Sócrates e centrada na arte apolínea, perdeu a capacidade de criar valores adequados ao tempo histórico. Assim, diferentemente da arte apolínea Nietzsche (2005b, p. 9) aposta no princípio da arte dionisíaca, em que "o homem não é mais artista, tornou-se obra de arte [...]”. Tudo o que o homem em sonho viu os deuses realizar, ele mesmo vive agora.

As discussões provocadas por Nietzsche renderam muitos debates e abriram novas perspectivas, inclusive para o campo educacional, na medida em que possibilitaram o emergir do outro enquanto outro, o que o constitui em uma das alternativas aos desafios contemporâneos da educação.

\section{A EMERGÊNCIA DO OUTRO}

“O emprego da palavra “outro” aparece associado ao estranho da identidade, a tudo que lhe é contrário, distinto e inverso" (HERMANN, 2011, p. 138). Emerge como um em si mesmo, como uma outra ontologia, num processo simultâneo de inclusão e exclusão. Por isso a "a alteridade é um outro, do qual depende a própria identidade. O outro e o eu estão numa relação complexa em que se remetem reciprocamente. Assim, o outro não só está fora como dentro do indivíduo” (HERMANN, 2006, p. 72). Mais do que isso, outro é possibilidade de relação por que como outro em si, é desde já é desafio e “interlocutor.” (LÉVINAS, 2004, p. 13). Encontro, é interlocução.
Deixado, de lado, subjugado, seja barbarizado, satanizado, esterizado ou esterelizado por discursos e práticas eugênicas, o outro que “[...] não possui destaque nem na metafísica nem na ética grega, embora seja analisado, de forma indireta, pelo princípio da identidade do ser" (HERMANN, 2014, p. 27), foi condicionado à identidade, caracterizado como não ser, como fonte do mal, castigado sem piedade, por um medo identitário, de a identidade perder. Mas foi esse outro, desde dentro e das margens do eu que fez ruir o paradigma dominante evidenciando sua doença, sua barbárie, no apelo a vida. Até então, "a dificuldade de lidar com o outro, e muitas vezes, seu aniquilamento, trouxe uma espécie de adoecimento, com desastrosas consequências para o plano político cultural e ético” (HERMANN, 2011, p. 3), visto que é também a dificuldade do eu lidar consigo.

O outro emerge assim, no cenário da modernidade a partir do princípio da subjetividade como o estranho de mim mesmo, como aquilo que ultrapassa a identidade do eu, como identidade própria, como outra ontologia. Irrompe “[...] como um relato de experiência poética, expondo o deslocamento de uma concepção metafísica da identidade para uma concepção enraizada nos contextos plurais do mundo da via, que se vê diante da alteridade, num eu que é atravessado pelo outro" (HERMANN, 2011, p. 138). Indica o estranho, aquilo que ultrapassa a identidade do eu.

Enfim, a ruptura da metafísica possibilitou emergir inúmeras possibilidades, vontades e vontades plurais. Se antes os valores eram tidos como atemporais e unos, agora emergem como temporais e plurais, não existindo mais uma única perspectiva, senão que perspectivas. Nesse contexto, na medida em que o outro como um em si ai torna-se possibilidade, emergem os desafios da inclusão não mais como adequação, mas como encontrar-se, pois o diferente, antes, tido como bárbaro é o outro que se efetiva enquanto outro ai, configurando um novo tempo, o tempo originário, que dos, nos encontros e desencontros faz brotar o humano no humanar, o amor no amar.

Nesse cenário, ganham importância as contribuições de Heidegger e de Gadamer, por possibilitarem a compreensão do fenômeno educativo para além da ruptura da metafísica, da pura diferenciação, no âmbito do diálogo.

\section{O ACONTECER ORIGINÁRIO ${ }^{\mathrm{i}}$ (FORMATIVO AUTOFORMATIVO)}

Mas, desde, já perguntamos pelas possíveis contribuições e limites de Heidegger ${ }^{\text {ii }}$ quanto à inclusão do outro como outro ai, como diversidade ontológica, num contexto de pluralidades ontológicas. Assim, como podemos evidenciar a presença como elemento constitutivo do acontecer primordial do humano, considerando que tal acontecimento constitui-se como acontecer formativo autoformativo do humano, dos diferentes que dos processos participam. A tese de Lévinas (2004, p. 33) de que "O humano só se oferece a uma relação que não é poder” é um dos elucidativos dos limites do pensamento Heideggeriano na medida que evidencia que neste o mesmo se efetiva em sua 
mesmeidade, pois em Heidegger “[...] a relação como o outro 'consiste em querer compreendê-lo, mas a relação (da alteridade) excede esta compreensão’. Significa que 'outrem não é, primeiramente, objeto de compreensão e depois, interlocutor’.” (LÉVINAS, 2004, p. 13), senão que, antes de tudo, o outro é interlocutor. Isso porque, "[...] a possibilidade do um-para-o-outro, um para o outro, que é o acontecimento ético” (LÉVINAS, 2004, p. 17).

Mas, Lévinas no encontro com Heidegger é um convite para a reflexão em torno das pluralidades ontológicas. Por isso abordaremos o outro ai, o eu ai como presenças, a realidade como possibilidade o que exige um repensar dos processos educativos e suas políticas. Mas o que significa a presença?

\section{a pre-sença não é algo simplesmente dado que ainda possui de quebra a possibilidade de poder alguma coisa. Primariamente, ela é possibilidade de ser. Toda pre-sença é o que ela pode ser e o modo em que é a sua possibilidade. A possibilidade essencial da pre-sença diz respeito aos modos característicos de ocupação com o 'mundo', de preocupação com os outros e, nisso tudo, à possibilidade de ser para si mesma, em função de si mesma (HEIDEGGER, 1995, p. 198-199).}

Agora, o outro é pre-sença, bem como o eu para o outro. A pre-sença, que desde seu "pré", de seu modo de ser e de aparecer como possibilidade, instaura o círculo da compreensão como um círculo formativo autoformativo, pois ultrapassa a pura epistemologia, a unilateralização dos elementos (sujeito/objeto, professor/aluno, ensino/aprendizagem). Mas, no encontro com as proposições de Lévinas, o círculo da compreensão $\mathrm{iii}$ proposto por Heidegger ainda pode ser referenciado?

Esses elementos, antes vistos e compreendidos em separado ou em uma estrutura hierárquica, agora somente podem ser compreendidos em relação um ao outro, mas numa relação estruturalmente aberta, em que seu ser verdadeiro se efetiva como ser-aí, no círculo da compreensão. Se pensadas, como encontros ontológicos constitutivos, porque no vir ao encontro vimos como possibilidade que pode se efetivar como acontecer para além do que lhes era viável sem o outro ai, sem o terceiro. Assim, no âmbito da alteridade podemos falar de ontologias, contexto em que "o dinamismo do pensar supõe a relação com o diferente, requer a mediação de um outro que, curiosamente, torna possível o discurso, o logos, a razão. [...] O outro [...] como o estrangeiro [...] é aquele que só pode comparecer na medida em que já provocou uma reação responsiva, no interior de uma esfera própria” (FABRI, 2006, 144). Assim, “a surpresa trazida pelo outro é uma espécie de impedimento da harmonização definitiva [...] (FABRI, 2006, p. 145)”, sempre rompendo com a mesmice do sistema exigindo o repensar de paradigmas. O outro é presença, como eu também o sou, e enquanto tal não é algo simplesmente dado, senão que é potencialidade, um ser e um poder ser algo, possibilidade, acontecimento, potencial de alteridade.

A emergência da diversidade, o aparecimento do outro enquanto outro ai diverso de mim chama atenção para que ultrapassemos a reificação do mesmo e a pura reificação do outro. Como é possível ultrapassar esta proposição? Ou como é possível a formação no horizonte do acontecer primordial do humano, sem nos obliterarmos em dificuldades e a diversidade configure sinônimo de conflito?

\section{O DIÁLOGO COMO MODO DE SER DO ACONTECER FORMATIVO AUTOFORMATIVO ORIGINÁRIO}

El encuentro con una gran obra de arte es siempre, diría yo, como un diálogo fecundo, un perguntar y un responder, o un ser perguntado y tener que responder; un diálogo verdadero, del cual algo ha salido y "permanece" (GADAMER, 2006, p. 193).

Como sinaliza Gadamer que o encontro com uma grande obra de arte é sempre um diálogo fecundo, do qual algo em emerge e permanece. Por outro, o encontro um outro dá o que falar, faz emergir algo, na media em que exige um ter que responder. Gera transformação em configuração, o que “[...] significa que algo se torna uma outra coisa, de uma só vez e como um todo, de maneira que essa outra coisa em que se transformou passa a constituir o seu verdadeiro ser, em face do qual o seu ser anterior é nulo. [...] significa que aquilo que era antes não é mais” (GADAMER, 2005, p. 166). Por isso, o “[...] um diálogo levado a sério, que não se oblitera em dificuldades, pressupõe entrar no jogo com o outro. A palavra que circula no diálogo desvela, questiona, configura identidades, demarca diferenças” (HERMANN, 2002, p. 94). Nesse sentido, o ser humano “tem o caráter de obra, do 'ergon' e não somente da ‘energia’” (GADAMER, 2005, p. 165).

O diálogo efetiva-se no horizonte do perguntar e do responder, à medida que vai colocando à prova os argumentos, as respostas e a própria pergunta. Assim, "opondo-se à rigidez das opiniões, o perguntar [o outro] põe em suspenso o assunto com suas possibilidades" (GADAMER, 2005, p. 479). Mas, a fim de que o diálogo se efetive, é necessário reconhecimento mútuo, participação dos envolvidos, abertura por partes dos que participam ou venham a participar do diálogo, de maneira fundamental. Devem estar dispostos a deixar valer algo contra si e isso a obra de arte cumpre. Implica abertura mútua, que só se efetiva com base na pertença. "Sem essa abertura mútua, tampouco pode existir verdadeiro vínculo humano. A pertença mútua significa sempre e ao mesmo tempo poder ouvir uns aos outros" (GADAMER, 2005, p. 472). Exige o reconhecimento de que o outro, a tradição, de que o eu, de que o presente tenha algo a dizer. Mais do que isso, que nenhum indivíduo, em sua subjetividade, contém a verdade, senão que a verdade emerge no jogo, como histórica. Isso 
requer “[...] a capacidade constante de voltar ao diálogo, isto é, de ouvir o outro, parece-me ser a verdadeira elevação do homem a sua humanidade” (GADAMER, 2004, p. 251). Ou seja, é a capacidade de efetivar-se no acontecer do ser como possibilidade pelo reconhecimento.

Podemos afirmar que o diálogo efetiva-se como o jogo, pois tem imbricado em seu ser a estrutura do perguntar e do responder. Por isso, o diálogo profundo, no encontro com o outro, ultrapassa a subjetividade de cada jogador e ganha vida própria, liberando o ser como devir, visto não ter um telos definido. E, "o que vem à tona, na sua verdade, [no encontro com o outro] é o logos que não é nem meu e nem teu [...]” (GADAMER, 2005, p. 480). Assim, no espírito do diálogo como no jogo em que o acontecer não tem dono, mas que depende da mutua participação, pois neste,

[...] os participantes vêem-se referidos, por assim dizer, enlaçados uns aos outros, sendo que jogo exige a entrega de cada um a um processo não dominável por nenhum dos participantes. Quem estiver, inicialmente, certo de ter elaborado o caminho mais adequado à vitória, vê-se surpreendido, de repente, por um lance inesperado do outro, ao qual não consegue, mas corresponder à altura. [...] o sentido nasce do "vir ao encontro" de um outro, eu-tu, eu-texto, eu-obra de arte, etc.” (FLICKINGER, 2003, p. 173)

A formação é “[...] o lugar onde essa fusão se dá constantemente, pois nela o velho [o eu] e o novo [o outro] sempre crescem juntos para uma validez vital, sem que um e outro cheguem a se destacar explícita e mutuamente” (GADAMER, 2005, p. 404-405). Agora, a educação, antes de ser um processo meramente reprodutivo, no horizonte do encontro com o outro, se efetiva como acontecimento produtivo autoformativo, não totalmente controlável, pois sempre compreendemos e nos efetivamos de modo diferente, com "história efeitual” (GADAMER, 2005, p. 396), em que a consciência se efetivada como finitude, no horizonte do acontecer originário, como temporalidade. Isso, porque, o homem que faz a experiência do outro, acolhe em si a plenitude dessa experiência, efetiva-se como historicidade e torna-se consciência efeitual: acontecer. Em consequência, a compreensão não se restringe ao desfrute reflexivo como ocorre no âmbito da distinção estética, porque a compreensão jamais é um comportamento subjetivo ante o objeto, mas um pertencer, um acontecer efeitual no encontro com o outro e consigo. "Mas o verdadeiro acontecer só se torna possível pelo fato de a palavra [o outro] que chega a nós como tradição [como outra tradição] e que devemos ouvir nos atingir realmente, como se fosse dirigida a nós e se referisse a nós mesmos” (GADAMER, 2005, p. 595-596). O outro nos coloca em jogo, como o eu coloca em jogo o outro, o terceiro que nos chega, podendo, ao mesmo tempo romper com a mesmeidade, com o círculo prévio da compreensão, como podendo este instalar. Por isso a palavra jogo constitui a melhor expressão.

\section{CONSIDERAÇÕES}

Frequentemente, a tradição ocidental, em suas várias experiências, aborda o outro como um perigo, como uma ameaça e não considera e tematiza em suas potencialidades, na medida em que também desconsiderou o eu, o que levou a considerar o educação, os processos educativos enquanto processos dirigidos, passíveis de controle como estratégia de formar o humano desejável e ideal.

A ruptura da metafísica constitui a possibilidade do emergir do outro no reconhecimento enquanto outro ai, a diversidade enquanto alteridade. Portanto, constitui as condições para o diálogo autêntico, enquanto acontecimento que não se oblitera em dificuldades, seja pelo conflito na diferenciação absoluta, seja enquanto síntese, seja enquanto disputa. Efetiva-se, enquanto processo produtivo autoformativo, na medida em que, quem dele participa, transforma-se em outro, num mútuo processo em que o horizonte comum se delineia o ser-ai, na media em que os participantes também se delineiam. O diálogo, demarca, configura, significa, resignifica identidades e horizonte comum, pois é acontecimento originário primordial em que o humano humana: é um acontecimento vital.

Assim, a partir da presença do outro e do eu, dos terceiros instala a possibilidade do dialogou autêntico, aquele que não se oblitera em dificuldades, em disputas, mas constitui-se como produtivo. Esse é o momento do acontecer primordial do humano: um acontecer autoformativo, que transcende a objetividade e objetividade dos processos. Do contrário, o eu enquanto eu puro fechado em mim mesmo petrifica, objetifica o outro e o eu; e, o outro enquanto outro puro em si, fechado em si mesmo petrifica o eu e a si. Mas, no autoreconhecimento, é possibilidade de autoformação. Desse modo, a escola, a sala de aula, os processos educativos podem se constituir, por excelência, num desses espaços originários, e as aulas como estes acontecimentos primordiais do humano.

Por último, o termo inclusão tensionado no início desse trabalho, mesmo nas acepções modernas e até contemporâneas, tem sido tomado como sinônimo de adaptação, de adequabilidade escondendo e maquiando, obscurecendo a "boa nova" trazida e possível pelo outro ai, pelos terceiros enquanto outro modo de ser, na medida em que vem se efetivando num processo de mesmeidade, de reificação do eu. Portando, o desafio que ora se desborda, se efetiva como diálogo autêntico.

\section{REFERÊNCIAS}

CHAUÍ, Marilena. (1991). Heidegger (1989-1976): vida e obra. In: Heidegger. Tradução e notas Ernildo Stein; Consultoria de Marilena Chauí. 4. ed. São Paulo: Nova Cultural.

FLICKINGER, Hans-Georg. (2003). O fundamento ético da hermenêutica contemporânea. Veritas, Porto Alegre, v. 48, n. 2, junho, p. 169-179. 
(2010). A caminho de uma pedagogia hermenêutica. Campinas-SP: Autores Associados.

GADAMER, Hans-Georg. (2005). Verdade e método I: traços fundamentais de uma hermenêutica filosófica. 7. ed. Petrópolis: Vozes; São Paulo: Editora Universitária São Francisco.

(2004). Verdade e método II: complemento e índice. 2. ed. Petrópolis: Vozes; São Paulo: Editora Universitária São Francisco.

(2007). Hermenêutica em retrospectiva: a virada hermenêutica. Trad. de Marco Antônio Casanova, Petrópolis: Vozes, 2007, v. II.

. (2006). Estética y hermenêutica. 3. ed., introdução de Angel Gabilondo e tradução de Antonio Gómez Ramos, Madrid - Espanha: Tecnos.

GIACOIA JUNIOR, Oswaldo. (2000). Nietzsche. São Paulo: Publifolha.

HEIDEGGER, Martin. (1995). Ser e tempo. Trad. de Márcia de Sá Cavalcante, Petrópolis: Vozes.

. (2010). A origem da obra de arte. Trad. de Idalina

Azevedo e Manuel de Castro. São Paulo: Edições 70.

HERMANN, Nadja. Pluralidade e ética em educação.

Rio de Janeiro: DP\&A, 2001.

Janeiro: DP\&A

(2002). Hermenêutica e educação. Rio de

. (2010). Autocriação e horizonte comum: ensaios

sobre a educação ético-estética. Ijuí: Unijuí.

. (2011). Breve investigação genealógica sobre o

outro. Educação \& Sociedade. Vol. 32, no. 114, Campinas jan./mar..

(2011). O outro na intersubjetividade. In.: BOMOBASSARO, Luiz Carlos; DALBOSCO, Cláudio Almir; KUIAVA, Evaldo Antonio. (2011). Pensar sensível. Porto Alegre: PUCRS.

HUSSERL, Edmund. (2008). Ideias para uma fenomenologia pura. 2. ed. São Paulo: Idéias \& Letras.

LÉVINAS, Emmanuel. (2014). Entre nós: ensaio sobre a alteridade. 3. Ed. Petrópolis/RJ: Vozes.

MOOSBURGER, Laura de Borba. (2007). A origem da obra de arte" de Martin Heidegger: tradução, comentário e notas. Dissertação (Mestrado em Filosofia)

- Universidade Federal do Paraná, Curitiba, 2007. Disponível em: <http://br.wrs.yahoo.com/_ylt=A0oG75MklZBNXD0B AJ7z6Qt.;_ylu=X3oDMTBybnZlZnRlBHNlYwNzcgR wb3MDMQRjb2xvA2FjMgR2dGlkAw--/SIG=145mlhl qu/EXP=1301407396/**http\%3a//dspace.c3sl.ufpr.br/ds pace/bitstream/1884/13434/1/A\%2520Origem\%2520da \%2520Obra\%2520de\%2520Arte\%2520pdf.pdf>.

Acesso em: 23 mar. 2011.

NIETZSCHE, Friedrich. (1989). Sujeito $e$ perspectivismo. Seleção de textos de Nietzsche - Notas introdutórias de Antonio Marques. Portugal: Publicações Dom Quixote LTDa.

(2005a). A gaia ciência. São Paulo: Companhia das Letras.

(2005b). A visão dionisíaca de mundo. São Paulo:

Martins Fontes. i Ursprung, em sua tradução para o português, tanto pode significar origem com originário.Emalemãoa palavra Ursprung é formada pela palavra springen que é pular mais o prefixo $U r$ - o primordial, em que a essência da identidade constitui o pulo primordial - acontecimento. Nesse sentido, "Origem diz uma proveniência marcada por um começo e uma causa identificável, inscrevendo-se, portanto, no tempo interpretado linear e historicamente. Metafisicamente o começo e a causa foram identificados com a essência metafísica. Já originário diz algo bem diferente, pois foge a uma interpretação metafísica. Não se identifica nem com começo nem com causa enquanto essência. Por isso, outra é a concepção do tempo. É um tempo poético-ontológico que consiste em estar sempre principiando e constituindo realidade. [...] Ele é sem fundamento, é Ab-grund, é abissal, é misterioso. É nesse sentido que o alemão diz Ur-sprung: o salto originário, primordial" (SILVA; CASTRO, 2010, p. 226).

ii Com base na tese de que a cultura ocidental gerou o esquecimento do ser na medida em que apostou no cientificismo, Heidegger revisou o grande projeto ocidental desde o retorno às coisas mesmas, proposto por Husserl, evidenciando que embora este tenha tematizado a questão do outro, não o fez sem pagar tributos ao cientificismo moderno. Para Husserl, inicialmente as coisas aparecem soltas e depois apareceu a consciência como unidade de sentido. Dessa forma, “[...] na visão dirigida sobre o objeto, temos, por exemplo, uma forma ou uma cor que permanece idêntica. Na atitude reflexiva, teremos os aspectos ou 'aparências' correspondentes, modalidades de orientação, de perspectiva, etc., que se sucedem numa sequência contínua” (HUSSERL, 2008, p. 57). Mas “a crítica heideggeriana visa à estreiteza de uma tal concepção de ser. [...]. O ser-aí não consiste na tentativa sempre ulterior de se colocar diante de si mesmo em meio ao tornar-se consciente de si. Ele é muito mais uma dação que se lança para além, e, em verdade, não apenas para as suas representações, mas antes de tudo para a não-dação do futuro (GADAMER, 2007, p. 18, v. II). De outra forma, “[...] a orientação pela subjetividade é tão determinante, que Husserl só conseguiu formular a partir daí até mesmo a colocação dos temas" (GADAMER, 2007, p. 19). Nisso constitui-se a diferença essencial entre Heidegger e Husserl, o que constitui a virada hermenêutica. Essa crítica de Heidegger a Husserl desemboca em uma crítica ao conceito de consciência como estrutura dogmática, para a qual Gadamer proporá a compreensão de consciência como consciência efeitual.

iii “O círculo não deve ser rebaixado a um vitiosum, mesmo que apenas tolerado. Nele se esconde a possibilidade positiva do conhecimento mais originário que, de certo, só pode ser apreendida de modo autêntico se a interpretação tiver compreendido que sua primeira, única e última tarefa é de não se deixar guiar, na posição prévia, visão prévia e concepção prévia, por conceitos ingênuos e "chutes". Ela deve, na elaboração da posição prévia, da visão prévia e concepção prévia, assegurar o tema científico a partir das coisas elas mesmas. Porque a compreensão, de acordo com seu sentido existencial, é o poder-ser da própria presença [...]” (HEIDEGGER, 1995, p. 210). 